International Journal of Engineering \& Technology, $7(2.8)(2018) 35-41$
International Journal of Engineering \& Technology
SPC
Website: www.sciencepubco.com/index.php/IJET
Research Paper

\title{
A comprehensive study on protection, control and communication techniques: a key concept for microgrid intelligent operation
}

\author{
C. Mahesh ${ }^{1}$, F. T. Josh ${ }^{2}$, A. Sanjeevi Gandhi ${ }^{3}$ \\ ${ }^{1}$ Research Scholar Department of Electrical Technology, Karunya Institute of Technology and Sciences Coimbatore, India. \\ ${ }^{2}$ Assistant Professor Department of Electrical Technology, Karunya Institute of Technology and Sciences Coimbatore, India. \\ ${ }^{3}$ Department of Electrical and Electronics Engineering, Karpagam College of Engineering \\ *Corresponding author E-mail:
}

\begin{abstract}
Microgrid is an integrated network of renewable and non renewable resources to supply the green power to a small range of community. An effective communication technology is necessary to be implemented among the power generations, storages and loads of microgrid in order to manage the load sharing, shedding and protection issues. This paper provides the study on architecture, characteristics, load managements, protection schemes, communication techniques and research challenges of microgrid.
\end{abstract}

Keywords: Renewable Resources; Microgrid; Communication; Management; Protection; Research Challenges; ETC.

\section{Introduction}

The utility grid is structured with three network systems such as, power generation, power transmission and power distribution. Here, the transmission network is delivering the generated power to distribution substation then the power will be distributed to consumers. A substantial amount of generated power is wasted as heat due to the long distance transmission and improper utilizations. Therefore, the smart grid is necessary to be implemented with power system in order to balance the energy generation and consumption [1]. A smartgrid is comprises the advanced sensing and actuator technology, intelligent control algorithms, effective communication infrastructure and self diagnosis for restoring power outrages [5]. The smartgrid structure is to have two ways communication between utility grid and consumers in order to supports protective operations, but the real time factors such as reliability, scalability and security are the major issues when it is come for the implementation. So that, the system has to be implemented with the facilities of local generation and storage at near the consumption premises and the name for the system is given as 'Microgrid'. A microgrid is comprises low voltage distribution system with distributed energy resources together with storage devices and flexible loads [2] and the integration of distributed generation units (DG) will affect the quality of the power and increase the voltage range in the grid by injecting the active power [3]. The implementations of microgrids are beneficial to the small community such as commercial facilities, residential and university campuses by applying the intelligent management to supply the connected loads and optimizing the energy usage [4]. As the use of renewable energy increases the system will be complicated to integrate and control the entire operations. So that, the communication infrastructure playing the major role in the microgrid to increase the grid integrity and stability. Figure 1 shows the implementation of a future microgrid with centralized management and wireless communications. 


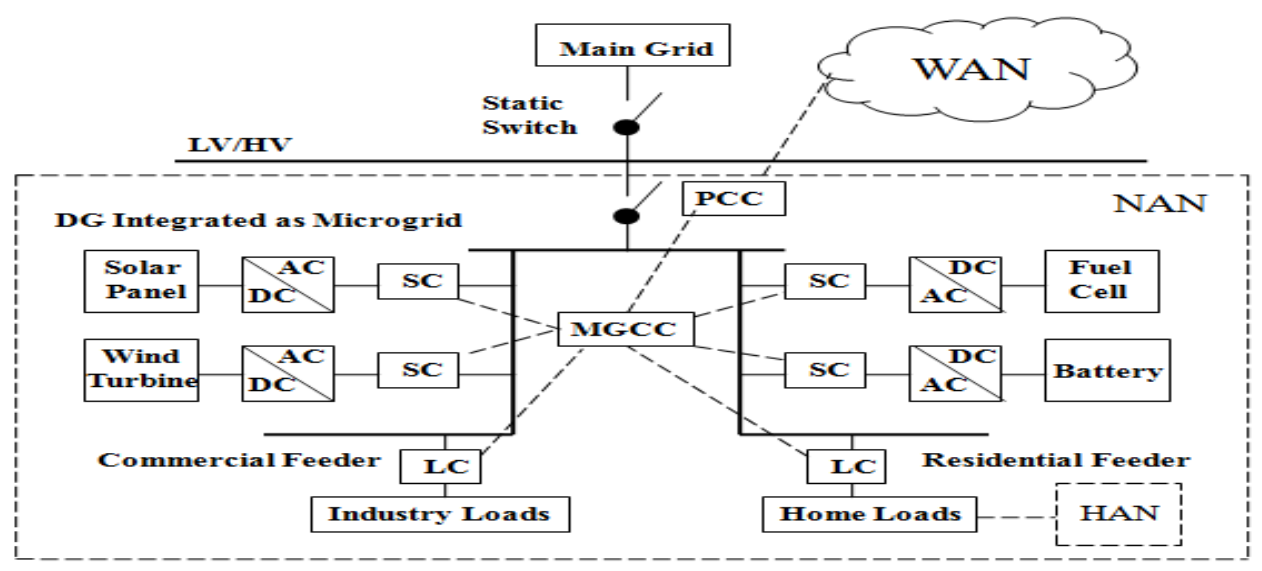

Fig. 1: Smart Microgrid Architecture.

-- Communication link

An integrated distributed energy network combines the electrical power electronic converters and controllers for intelligent management. The primary controller of a microgrid is MGCC (Microgrid Central Controller) which responsible for managing high level tasks. The Point of Common Coupling (PCC) is normally a static switch to connect the microgrid with utility grid. Source and Load controllers (SC and LC) are the secondary level controllers to connect the different generation units to the feeders based on power demands [8].

\section{Microgrid characteristics}

A microgrid is a local power system which equipped with generation, loads and demand all together connected in a controlled network. The microgrid can operate on grid connected mode and it can also be operate on independently (island mode). When a microgrid is operating on island mode it can be act as a self sustaining power system and demand has modulated through an intelligent control system which adopted by demand response (DR)[7] In order to provide smooth and reliable flow of the power a microgrid incorporates some of the following principal characteristics.

- Must be facilitated by self healing mechanism in order to detect, analyze and respond to the fault.

- The microgrid management system must be user friendly and make the customers to participate into grid operations.

- Microgrid power system should be delivering the green power that satisfies the power consumers.

- An intelligent system which implemented with a microgrid should be resilient to cyber and physical attacks.

- $\quad$ The microgrid power network must be structured with plug and play approach in order to accommodate variety of distributed generation (DR) and storage options.

By the virtue of being a self automated system, a microgrid is resilient to the power supply interruptions and the timeframe of this characteristics differ from a system which operate on grid independent mode and it can operate for long period depends on the availability of renewable energy. The penetration of renewable sources brings more benefits to the grid in terms of delivering the sustainable power and setting up the schedule with a range of demand requirements and by shedding the non critical demands the system can manage the critical loads. In microgrid the conversion losses avoided by feeding DC loads using DC sources such photovoltaic system and the distribution network losses reduced by the local use of energy [6].

\section{Microgrid load management}

The total loads of a microgrid can be measured easily as the sum of energy generated by DG and the amount of energy imported through PCC (Point of Coupling). When a microgrid is operated on grid connected mode, often the distributed generation is less than the microgrid total load due to the maintenance of generators or the economics on power production [9]. The loads such as, heaters, refrigerators, freezers, air conditioners, etc. of a distributed power system are controlled by load management programs (LMP) including direct load control (DLC) and interruptible load management (ILM). Other loads like battery, heat storage unit and vehicle to grid (V2G) are taking major part in the LPM [11], [13]. A large number of distributed generations (DG's) and renewable energy resources (RES) can be connected to the utility grid with the help of smart grid technology but, the necessary development is needed in managing the distribution network when large numbers of RES are integrated. It can be done with the help of microgrid (MG) and virtual power plant (VPP) concepts [12]. Authors Jingshuang Shen,t Bosong $\mathrm{Li}$ has discussed about various controllable loads and types of load management approaches in [47].

Type I of Controllable loads: This includes residential loads such as, water heater, air conditioner; refrigerator, washing machine etc. and these are interrupted by load utility monitor and the load curves can be modified by reducing the demand. These are the loads can be called as passive controllable loads, because it cannot inject the power to utility grid at any time [47].

Type II of Controllable loads: These types of loads are active controllable loads includes CCHP (Combine Cooling Heating Power) and Vehicle to Grid etc. It can be inject the power to grid, addition it has the flexibility to schedule as controllable loads [47], [48].

Type II of Controllable loads: These types of loads are broad controllable loads includes microgrid and VPP etc. Although, the microgrid and VPP are integrated with DGs, storage device, renewable sources etc. They are mainly demanding the power from the utility grid during grid connected mode [47].

DLC (Direct Load Control), ILM (Interruptible Load Management) are the common load management strategy in distributed power system. DLC can easily reshape the load curve by cycling the large current appliances at the user side such as, water heaters, freezers, heaters etc. However, interruptible loads are noticeable at the consumer side, but generally the DLC can be controlled it without noticeable on consumers i.e. the system monitors the utility and sends an ON/OFF commands directly to smart appliances [55]. The deployment of smart meters in the microgrid facilitates the customers to participate in DSM (Demand Side Management) by the development of real time communication between smart devices and distributor. DLC strategy is mainly focusing on demand response and renewable energy like solar and wind power. 
Authors Wei Huang, Miao Lu, Li Zhang are discussed many control strategy in reference [56] and are summarized as central bi level control, aggregator and hybrid coordination control. A microgrid may include with different types of controllable loads, but bi level control strategy is only suitable for the loads which are having same characteristics. Aggregator is serving as a central controller, it collecting information from the grid and controllable loads and also it provide regulated management by connecting grid operator and smart appliances. Table 1 shows the summary of controllable loads.

Table 1: Summary of the Controllable Loads [9-13, 44 - 56].

\begin{tabular}{|c|c|c|c|c|c|}
\hline Item & DLC & $\begin{array}{l}\text { Interruptible } \\
\text { load }\end{array}$ & $\begin{array}{l}\text { Store } \\
\text { battery }\end{array}$ & V2G & CCHP \\
\hline Power & Passive & Passive & Active & Active & Active \\
\hline $\begin{array}{l}\text { Store excess } \\
\text { energy }\end{array}$ & No & No & Yes & Yes & Yes \\
\hline $\begin{array}{l}\text { Send energy to } \\
\text { grid }\end{array}$ & No & No & Yes & Yes & Yes \\
\hline Peak saving & Yes & Yes & Yes & Yes & Yes \\
\hline Valley filling & Yes & No & Yes & Yes & Yes \\
\hline $\begin{array}{l}\text { Meeting sudden } \\
\text { demands }\end{array}$ & Yes & Yes & Yes & Yes & Yes \\
\hline V\&F Control & Yes & Yes & Yes & Yes & Yes \\
\hline $\begin{array}{l}\text { Effectiveness to } \\
\text { increase pene- } \\
\text { tration }\end{array}$ & Good & Kind & Better & Better & Good \\
\hline $\begin{array}{l}\text { Controllable } \\
\text { loads cost }\end{array}$ & Low & Low & High & Low & Low \\
\hline
\end{tabular}

\section{Microgrid protection schemes}

The two different levels of protection schemes required for microgrid. One is, when the microgrid is operates on grid connected mode and other one is when the microgrid is operates on autonomous mode. The protection issues on the grid connected mode are lag in the response time of circuit breakers at PCC (Point of Common Coupling) or by the false tripping of an isolation devices and the reconnecting speed of the microgrid with utility grid after the fault rectification. Therefore, the protection system must be proactive to the changes happening in the microgrid operations [10]. The different level of microgrid protection schemes which are in the trends discussed as follows,

i) Adaptive Protection: In this protection scheme an intelligent electronic devices (IED) are used as protective relay and it can be configured by several settings which correspond to different operating states of the protection system. Adaptive is an on-line protection scheme where the modification for the preferred relay settings can be done in order to provide the response to the system changes [14]. The tripping characteristics (configurations) of numerical relay are well suited for the practical implementation of an adaptive protection system and the standard communication protocol can create the required coordination among the relays. So that an individual relay can get the communication with microgrid central controller (MGCC) or between different relays. In this method of protection, the relay settings are adopted to various operation status of microgrid and to different operating modes. The following problems are associated with the practical implementation adaptive protection strategies in microgrid [16], [27].

- The establishment of communication infrastructure among the protective relays (IED) and MGCC is very costly.

- There will be complications in short-circuit and fault current calculation with different operating modes of microgrid.

- Possible configuration must be tested before the implementation of a protection strategy by keeping the microgrid in off-line.

- The necessary configuration must be updated with the IED even if it is in the utilization currently.

ii) Differential Protection: In this protection scheme the current transformer and relay are used to ensure the fault in the line by comparing the value of high frequency sampled current which measured at both end of the line. The protection relay will be trip if there is any difference between the samples above the threshold. During the fault nil conditions the return value of the sensors which measured from all the lines and nodes will be zero [28]. By sensing zero and negative sequences of current, this protection method will detect the single phase LL (Line to Line) and LG (Line to Ground) faults in the Microgrid network [24]. As a future microgrid concept, an intelligent relay has been developed to be operated in 50ms time and it will be located at both end of the line to protect the microgrid in both grid connected and autonomous mode of operation. The method of protection by keeping the relay at both end of the feeder will provides robust protection to the microgrid and as a developed strategy the PLC (Power Line Carrier) communication based protection method has been implemented in order to provide protection not only for feeder and also provide the solution to buses and DG sources [44].

iii) Distance protection: This method of protection system has implemented with distance relays which are capable of measuring line impedance $(\mathrm{Z})$ of a length of a feeder to a predetermined point and it has designed with inverse time tripping characteristics to respond only for the faults which are occurred between the relay points and also it has the ability to isolate the faulty in the both modes of microgrid operation [42]. It is important that the communication between distributed generators should be effective for ensuring selectivity and proper clearing of faults [45].

iv) Voltage Protection: In this protection scheme, the output voltage of DG sources are measured then converted as DC quantity by $\mathrm{d}-\mathrm{q}$ reference frame to protect the microgrid against Zone-in and Out-of-Zone faults. The protection method of this scheme does not depend on communication system which deployed in the network using pilot wires, optical fibers or Ethernet and the salient feature of this one is adoptable for various configurations of microgrids [24, 28]. To protect microgrid in both grid connected and autonomous mode of operations, a new protection method based on busbar voltage analysis and the direction of faults has discussed in [46], the author designed relay hardware/software using IPCs (Industrial Personal Computers). 
Table 2: Comparison of Microgrid Protection Schemes [24 - 28, 37 - 44].

\begin{tabular}{|c|c|c|c|c|c|c|}
\hline $\begin{array}{l}\text { Protection } \\
\text { Scheme }\end{array}$ & Relay Used & $\begin{array}{l}\text { Operation } \\
\text { Mode }\end{array}$ & DG Type & $\begin{array}{l}\text { Comm. } \\
\text { Link }\end{array}$ & Merits & Demerits \\
\hline Adaptive & $\begin{array}{l}\text { Directional } \\
\text { OC Relay }\end{array}$ & Islanded & $\begin{array}{l}\text { Inverter } \\
\text { based }\end{array}$ & Yes & $\begin{array}{l}\text { Fast protection in all } \\
\text { operating modes. }\end{array}$ & $\begin{array}{l}\text { - Applicable for island- } \\
\text { ed mode of operation only. }\end{array}$ \\
\hline $\begin{array}{l}\text { Differential } \\
\text { current }\end{array}$ & Digital Relay & $\begin{array}{l}\text { Grid connect- } \\
\text { ed, Islanded }\end{array}$ & $\begin{array}{l}\text { Rotating } \\
\text { and In- } \\
\text { verter } \\
\text { based }\end{array}$ & Yes & - ' $Z$ ' fault. $\quad$ Ability to detect high & High implementation \\
\hline Distance & $\begin{array}{l}\text { Distance } \\
\text { Relay }\end{array}$ & $\begin{array}{l}\text { Grid connect- } \\
\text { ed, Islanded }\end{array}$ & $\begin{array}{l}\text { Inverter } \\
\text { based }\end{array}$ & No & $\begin{array}{l}\text { Zone protection is } \\
\text { depends on the ' } Z \text { ' of lines. }\end{array}$ & $\begin{array}{l}\text { - Unnecessary relay } \\
\text { tripping for the ground faults if } \\
\text { the star connected load down- } \\
\text { stream to the fault. }\end{array}$ \\
\hline Over current & OC Relay & $\begin{array}{l}\text { Grid Con- } \\
\text { nected }\end{array}$ & $\begin{array}{l}\text { Rotating } \\
\text { and In- } \\
\text { verter } \\
\text { based }\end{array}$ & No & $\begin{array}{l}\text { No changes require } \\
\text { on existing protection relay. }\end{array}$ & $\begin{array}{l}\text { - Not suitable for is- } \\
\text { landed mode. }\end{array}$ \\
\hline $\begin{array}{l}\text { Symmetrical } \\
\text { current }\end{array}$ & OC Relay & Islanded & $\begin{array}{l}\text { Inverter } \\
\text { based }\end{array}$ & No & $\begin{array}{l}\text { Providing effective } \\
\text { protection for LL and SLG } \\
\text { faults. }\end{array}$ & $\begin{array}{l}\text { Single phase tripping } \\
\text { not allowed, Three phase faults } \\
\text { not considered. }\end{array}$ \\
\hline Voltage & - & Islanded & $\begin{array}{l}\text { Inverter } \\
\text { based }\end{array}$ & Yes & $\begin{array}{l}\text { Separate protection } \\
\text { for Generators. }\end{array}$ & $\begin{array}{l}\text { Single phase and high } \\
\text { ' } Z \text { ' faults not considered. }\end{array}$ \\
\hline Harmonics & - & Islanded & $\begin{array}{l}\text { Inverter } \\
\text { based }\end{array}$ & Yes & - & $\begin{array}{l}\text { - Trip to fail if more dynamic } \\
\text { loads in the network. }\end{array}$ \\
\hline $\begin{array}{l}\text { Current travel- } \\
\text { ling waves }\end{array}$ & - & $\begin{array}{l}\text { Grid connect- } \\
\text { ed }\end{array}$ & - & No & $\begin{array}{l}\text { Independent from } \\
\text { high fault current and power } \\
\text { flow direction. }\end{array}$ & $\begin{array}{l}\text { - No simulation work } \\
\text { has conducted. }\end{array}$ \\
\hline
\end{tabular}

\section{Communication techniques}

The reliable and scalable communication network is required for monitoring power lines in real time to protect the power systems from natural disasters. Mainly, it provides the facility to service providers in order to access electricity usage data remotely. PLC (Power Line Carrier), DSL (Digital Subscriber Line) and Fiber optical, these are the available broadband technologies which employed between control center and smart meters [73]. PLC is a well suited cost effective medium for the utility when the distributed feeders are considered and it can transmit the data at maximum rate of $11 \mathrm{kbps}$ only at (9-95) $\mathrm{KHz}$ narrow frequency. This rate of communication may not enough to support applications where large amount of data to be transferred. Newly developed power system network could be implemented with fiber optic network very close to feeders, thus enable the communication infrastructure for both utility and consumers [77]. PSTN (Public Switched Telephone Network) is another wired option which provides simple, highly reliable and inexpensive solution with bidirectional communication, but it is limited by the bandwidth which offered. So that the developed countries moving away from PSTN to wireless technologies. The feasibility of this technology is leading the communication without any physical connection between numbers of nodes. As a wireless communication technology the HAN (Home Area Network), NAN (Neighborhood Area Network) and WAN (Wide Area Network) are playing major role in monitor and control the operation of the Grid at distributed level [80], [81].

Home Area Network (HAN): Home appliances which needed to be automated are connected at HAN level. In the case of SG (Smart Grid), HAN is the lower level communication network of the overall infrastructure, for example connecting smart meters and control devices for integrating DGs to microgrid, plug in hybrid electric vehicle and to implement DR applications. Its coverage range is limited to ten meters only.

Neighborhood Area network (NAN): This network acting as gateway between HAN and upper level communication devices and frequently its transmitting the data information between customers, delivered from different HANs and aggregation points Therefore the range of NAN network is around thousands of me- ters and particularly this range of communication is well suitable for medium size electrical grid (MG).

Wide Area network (WAN): WAN is the backbone for smart microgrid network and the main task of this network is transmitting all the collected data information to grid operator and commanding the consumers. Thus WAN must be abled to handle and carry larger amount of data information to wide range.

HAN and NAN levels communication networks includes the low power wireless technologies such as Bluetooth, ZigBee, and Wifi etc. The physical layer of Bluetooth technology is defined by IEEE 802.15.1 standard and it has designed to be operating on personal area networks (PANs), the coverage of this technology is $10 \mathrm{~m}$ only but it can be extended to $100 \mathrm{~m}$ by adding repeaters and increasing the data rates about $720 \mathrm{kbps}$. In HAN network this protocol providing greatest solutions to interface smart meters to customer devices [76]. The physical layer of ZigBee protocol is defined by IEEE 802.15.4 standard and it is well adopted for framing mesh network and low duty cycle applications, without any repeaters this can cover the range of $100 \mathrm{~m}$ for the data rate about 250kbps. This technology using ISM frequency bands such as 868 $\mathrm{MHz}, 915 \mathrm{MHz}$ and $2.4 \mathrm{GHz}$ for data transmission and it is considering as one of the suitable technology for networking the devices in HANs [84], [85]. Wifi is the cost effective, high data rate communication protocol which defined by IEEE 802.11 standards, the characteristics of Wifi make attractive communication for NAN networks. Coverage of the Wifi is around $200 \mathrm{~m}$ and the high power consumption only considered as its drawback [79]. Table 3 shows the comparison statements of wireless technologies. Controllers analysis for non-linear system has been reported [96-108]. 
Table 3: Comparison of Wireless Communication Technologies [73 - 85]

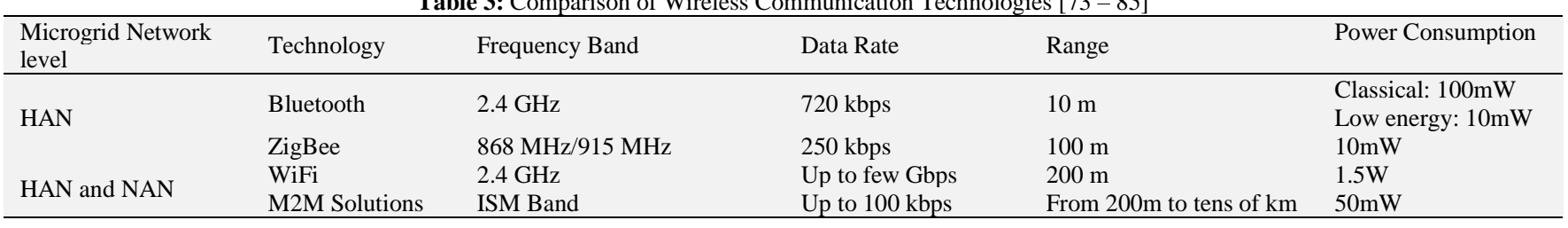

\section{Conclusion}

This paper has surveyed the key concepts which concerning electrical microgrids and protection schemes, load managements, and wireless networks in order to transform a classical small scale grid into a smart microgrid. Microgrids (MGs) are the paradigm of the new smart electrical grid (SGs) that includes effective management and control strategies, penetration of renewable energy resources, energy storages, and power unbalance risk. In order to assure an intelligent operation for a microgrid, it is necessary to be implement with an effective protection schemes, well coordinated communication between LC, SC, MGCC and grid operator by deploying smart sensors and actuators in the distributed level network.

\section{References}

[1] A.Salehi Dobakhshari, S.Azizi, A.M.Ranjibar, "Control of Microgrids: Aspects and Prospects", IEEE International Conference on Networking, Sensing and Control, pp 21 - 24, 2011.

[2] Rengaraju, Anand Srinivasan, "Communication Requirements and Analysis of Distribution Networks Using WiMAX Technology for Smartgrid", IEEE 8th International Conference on Wireless Communications and Mobile Computing, pp. 43 - 47, 2012.

[3] Alvaro Llaria, Guillaume Terrasson, Octavian Curea, Jaime Jimenez, "Application of Wireless Sensor and Actuator Networks to Achieve Intelligent Microgrids: A Promising Approach towards a Global Smartgrid Deployment", International Journal of Applied Sciences, pp. 1 23, 2016.

[4] Song Ci, Qian Junjie, "Impact of Wireless Communication Delay on Load Sharing among Distribution Generation Systems through Smart Microgrids ", IEEE Wireless Communications, pp. 24 - 29, 2012.

[5] G. Stanciulescu, H. Farhangi, A.Palizban, N. Stanchev, "Communication Technologies for the BCIT Smart Microgrid, IEEE International Conference on Elctro/Information Technology, pp. 13 - 16, 2011.

[6] Cai Changchun, Deng Lihua, Dai Weili, "Characteristic Mode based Microgrid Equivalent Modeling", IEEE International Conference on Power System Technology, pp. 2901 - 2909, 2014

[7] Jinkai li, Bo Shen, Jin Zhang, Pei maio, Dinyan Cai, "Characteristics and Application of Distributed energy and Microgrid : Based on Information Technology", International Journal of Information Technology, pp. $5231-5237,2013$.

[8] Manzar Ahmed, Uzma Amin, "Integration of Renewable Energy Resources in Microgrid" Energy and Power Engineering, Scientific Research Publishing, pp. 12 - 29, 2015.

[9] Bill Moran, Senior Electrical Engineer, TRC Companies Inc., Lowell MA, USA, "Microgrid Load Management and Control Strategies", IEEE/PES Transmission and Distribution Conference and Exposition (T\&D), pp. 7 - 11, 2016.

[10] [ushiq Ali Memon, Kimmo Kauhaniemi, "A Critical Review of AC Microgrid Protection Issues and Available Solutions" International Journal of Electric Power Systems Research, pp. 23 - 31, 2015.

[11] Jingshuang Shen, Chuanwen jiang, Bosong Li "Controllable Load Management Approaches in Smart Grids" International Journal of Energies, pp. 11187 - 11202, 2015.

[12] Kondoh, J.Direct Load Control for Wind Power Integration. In proceedings of the IEEE Power and Energy Society General Meeting, San Diego, CA, USA, pp. $1-8, \quad 2011$ https://doi.org/10.1109/PES.2011.6039480.

[13] Si W Li, Y, "Modeling and Implementation of Incentive Interruptible Load Contracts in Electricity Markets. In preceding of the AsiaPacific Power and Energy Engineering Conference (APPEEC) Chengdu, China, pp. 28-31, 2010"

[14] Hannu Laaksonen, Dimitry Ishchenko, Alexandre Oudalov, "Adaptive Protection and microgrid Control Design for Hailuoto Island",
IEEE Transaction on Smart grid, pp 1486 - 1493, 2014 https://doi.org/10.1109/TSG.2013.2287672.

[15] Ahmad Razani Haron, Azah Mohamed, Hussain Shareef, "Coordination of Overcurrent, Directional and Differential Relays for the Protection of Microgrid System", International Conference on Electrical Engineering and Informatics (Elsevier), pp. 366 - 373, 2013.

[16] Sohrab Mirsaeidi, Dalila Mat Said, Mohd Wazir Mustafa, Mohd Hafiz Habibuddin, "Review and Analysis of Existing Protection Strategies for Microgrids", International Journal of Electrical Systems, pp. $1-10,2014$.

[17] Ahmad Razani Haron, Azah Mohamed, Hussain Shareef "A Review on Protection Schemes and Coordination Techniques in Microgrid System”, International Journal of Applied Sciences, pp. 101 - 112, 2012. [18] [18] Keng-Yu Lien, Duong Minh Bui, Yung-Ruei Chang, YihDer Lee, Jheng-Lun Jiang, "Available Fault Protection Methods of Ungrounded AC Microgrids Evaluated by Transient Simulation Results", International Journal of Computer and Electrical Engineering(Elsevier), pp. $84-103,2016$

[19] Gnana Swathika O.V, Hemamalini S, (2016) "Review on Microgrid and Its Protection Strategies", International Journal of Renewable Energy Research (Scopus), pp. 1574 - 1587, 2016.

[20] Taha Selim Ustan, Cagil Ozansoy, Aladin Zayegh, "Modeling of a Centralized microgrid Protection System and Distributed Energy Resources According to IEC 61850 - 7 - 420", IEEE Transaction on Power Systems, pp. $1560 \quad$ - $1567, \quad 2012$ https://doi.org/10.1109/TPWRS.2012.2185072.

[21] Jae-Do, Jared Candelaria, "Fault Detection and Isolation in Low-Voltage DC Bus Microgrid System", IEEE Transaction on Power Delivery, pp. $779-787,2013$

[22] Zongrui Ding, Yuanxiong, Dapeng Wu, Yuguang Fang, "A Market based Scheme to Integrate Distributed Wind Energy", IEEE Transaction on Smart grid, pp $976-984,2013$. https://doi.org/10.1109/TSG.2012.2230278.

[23] Jae-Do, Jared Candelaria, Liuyan Ma, Kyle Dunn, "DC Ring Bus Microgrid Fault Protection and Identification of Fault Location", IEEE Transaction on Power Delivery, pp. 2574 - 2584, 2013

[24] Sortomme E, Ren J, Venkata S.S, "A Differential Zone Protection Scheme for Microgrids", IEEE Power and Energy Society General Meeting (PES), pp. 1-5, 2013.

[25] C. Mahesh, F.T.Josh, "A Comprehensive Study on Distributed Energy Generation Integration Technology", Proceeding of IEEE International Conference on Innovations in Electrical, Electronics, Instrumentation and Media Technology (ICIEEEIMT'17), pp. 49 - 56, 2017. https://doi.org/10.1109/ICIEEIMT.2017.8116874.

[26] M.Khederzadeh, Adaptive Setting of Protective Relays in Microgrid in Grid Connected and Autonomous operation, 11th International Conference on Developments in Power Systems Protection (DPSP), pp. 1 - 4, 2012. https://doi.org/10.1049/cp.2012.0076.

[27] E.Sortomme, S.S.Venkata, J.Mitra, Microgrid Protection Using Communication Assisted Digital Relays, IEEE Transaction on Power Delivery, pp2789. - 2796, 2010.

[28] Sitharthan R, Geethanjali M, Karpaga Senthil Pandi T “Adaptive Protection Scheme for Smart Microgrid with Electronically Coupled Distributed Generations", Alexandria Engineering Journal, pp.2539 - 2550 2016.

[29] Zhao Xiao-Xiao, Xia Ming-Chao, He Xuan-hu, Zhou Yuan "Study on Protection Scheme for Microgrid with Mobile Energy Storage Units", International Workshop on Automobile, Power and Energy Engineering,pp. 192 - 197, 2011.

[30] Ahmad Razani Haron, Azah Mohamed, Hussain Shareef "Coordination of Overcurrent, Directional and Differential Relays for the Protection of Microgrid System", International Conference on Electrical Engineering and Informatics (Elsevier), pp.366 - 373, 2013.

[31] Sohrab Mirsaeidi, Dalila Mat Said, Mohd Wazir Mustafa, Mohd Hafiz Habibuddin, "Review and Analysis of Existing Protection Strategies for Microgrids", International Journal of Electrical Systems, pp. $1-10,2014$

[32] Ahmad Razani Haron, Azah Mohamed, Hussain Shareef "A Review on Protection Schemes and Coordination Techniques in Microgrid System", International Journal of Applied Sciences, pp.101 - 112, 2012. 
[33] Keng-Yu Lien, Duong Minh Bui, Yung-Ruei Chang, Yih-Der Lee, Jheng-Lun Jiang, (2016) "Available Fault Protection Methods of Ungrounded AC Microgrids Evaluated by Transient Simulation Results", International Journal of Computer and Electrical Engineering, pp.84 - 103, 2016.

[34] Gnana Swathika O.V, Hemamalini S, "Review on Microgrid and Its Protection Strategies", International Journal of Renewable Energy Research, pp.1574 - 1587, 2016.

[35] Taha Selim Ustan, Cagil Ozansoy, Aladin Zayegh, "Modeling of a Centralized microgrid Protection System and Distributed Energy Resources According to IEC 61850 - 7 - 420", IEEE Transaction on Pow-

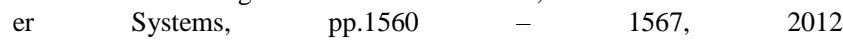
https://doi.org/10.1109/TPWRS.2012.2185072.

[36] Jae-Do, Jared Candelaria, "Fault Detection and Isolation in Low-Voltage DC Bus Microgrid System", IEEE Transaction on Power Delivery, pp.779 - 787, 2013.

[37] Zongrui Ding, Yuanxiong, Dapeng Wu, Yuguang Fang, "A Market based Scheme to Integrate Distributed Wind Energy", IEEE Transaction on Smart grid, pp.976 - 984, 2013 https://doi.org/10.1109/TSG.2012.2230278.

[38] Jae-Do, Jared Candelaria, Liuyan Ma, Kyle Dunn, "DC Ring Bus Microgrid Fault Protection and Identification of Fault Location", IEEE Transaction on Power Delivery, pp.2574 - 2584, 2013.

[39] Sortomme E, Ren J, Venkata S.S, “A Differential Zone Protection Scheme for Microgrids", IEEE Power and Energy Society General Meeting (PES), pp.1 - 5, 2013.

[40] Hannu Laaksonen, Dimitry Ishchenko, Alexandre Oudalov, "Adaptive Protection and microgrid Control Design for Hailuoto Island", IEEE Transaction on Smart grid, pp.1486 - 1493, 2014. https://doi.org/10.1109/TSG.2013.2287672.

[41] Zeineldin H, El-Saadany, Salama MA, "Distributed Generation Microgrid Operation: Control and Protection", IEEE Power System Conference on Advanced Metering, Protection, Control, Communication and Distributed Resources, pp.105-111, 2010.

[42] Hussain B, Sharkh S, Abusara M, "Integration of Distributed Generation into the Grid Protection Challenges and Solutions" 10th IET International Conference on Developments of Power System Protection, pp.1 - 5, 2010. https://doi.org/10.1049/cp.2010.0347.

[43] Wang X, Li Y, Yu Y, "Research on the Relay Protection System for a Small Laboratory-Scale Microgrid System" Industrial Electronics and Application (ICIEA), 6th IEEE Conference, pp.2712 - 2716, 2011. [44] Jingshuang Shen, Chuanwen Jiang, Bosong Li, "Controllable Load management Approaches in Smart Grids" International Journal of Energies, pp. 11187 - 11202, 2015.

[45] Koutitas G, Tassiiulas L, "Periodic Flexible Demand: Optimization and Phase management in the Smart Grid" IEEE Transaction on Smart Grid, pp.1305 - 1313, 2013.

[46] Manzar Ahmed, Uzma Amin, "Integration of Renewable Energy Resources in Microgrid" Energy and Power Engineering, Scientific Research Publishing, pp 12 - 29, 2015.

[47] Eklas Hossain, Erasan Kabalci, "A Comprehensive Study on Microgrid Technology" International Journal of Renewable Energy Research, pp.1012 - 1017, 2014

[48] Lidula, Rajapakse, "Microgrid Research: A Review of Experimental Microgrids and Test Systems" Renewable and Sustainable Energy Reviews, pp 186 - 202, 2011. https://doi.org/10.1016/j.rser.2010.09.041.

[49] Farret F.A, Simoes M.G, "Integration of Alternative Sources of Energy" John Wiley and Sons, Hoboken, pp.112 - 117, 2006 https://doi.org/10.1002/0471755621.ch5.

[50] Alvaro Liaria, Guillaume Terrasson, "Application of Wireless Sensor and Actuator Networks to Achieve Intelligent Microgrids: A Promising Approach towards a Global Smart Grid Deployment" Applied Science MDPI, pp. 1 - 23, 2016.

[51] Planas E, Gil-De-Muro, Andreu, "General Aspects, Hierarchical Controls and Droop Methods in Microgrids" A Review on Renewable, Sustainable Energy Rev. pp 147 - 159, 2013.

[52] Palensky P, Dietrich D, "Demand Side Management: Demand Response, Intelligent Energy Systems and Smart Loads" IEEE Transaction Ind. Inform. pp 381 - 388, 2011.

[53] Wei Huang, Miao Lu, Li Zhang, "Survey on Microgrid Control Strategies" Energy Procedia, vol.12, pp 206 - 212, 2011 https://doi.org/10.1016/j.egypro.2011.10.029.

[54] F.Katiraei, R.Iravani, N.Hatziargyriou, A.Dimeas "Microgrids Management" IEEE power and Energy Magazine, vol.6, pp 54 - 65, 2008. https://doi.org/10.1109/MPE.2008.918702.

[55] Guerrero J.M, "Connecting Renewable Energy Sources into the Smartgrid" IEEE International Symposium on Industrial Electronics (ISIE), pp 2400 - 2566, 2011. https://doi.org/10.1109/ISIE.2011.5984420.

[56] Jackson John Justo, Francis Mwasilu, Ju Lee, Jin Woo Jung, “AC - Microgrids Versus DC - Microgrids with Distributed Energy Re- sources: A Review" Renewable and Sustainable Energy Reviews, vol.24, pp 387 - 405, 2013. https://doi.org/10.1016/j.rser.2013.03.067.

[57] Blaabjerg F, Teodorescu R, Lissere M "Overview of Control and Grid Synchronization for Distributed Power Generation Systems" IEEE Transaction Ind Electron, vol.5, pp 1398 - 1409, 2006. https://doi.org/10.1109/TIE.2006.881997.

[58] Yazdani A, Iravani R "Voltage - Sourced Converter in Power Systems: Modeling, Control and Application" Wiely, New York, 2010. https://doi.org/10.1002/9780470551578.

[59] Yunwei LI, Farzam Nejabatkhah "Overview of Control, Integration and Energy Management of Microgrids" J. Mod. Power Syst. Clean Energy (Springer), vol.2, pp 212 - 222, 2014.

[60] Carrasco JM, Franquelo LG, Bialasiewwicz JT "Power - Electronic Systems for the Grid Integration of Renewable Energy Sources: A Survay" IEEE Transaction Power Electron, vol.4, pp 1002 - 1016, 2006.

[61] Guangqian DING, Feng GAO, Song ZHANG, Poh Chiang LOH "Control of Hybrid AC/DC Microgrid under Island Operational Conditions" J. Mod. Power Syst. Clean Energy (Springer), vol.2, pp 223 232, 2014. https://doi.org/10.1007/s40565-014-0065-z.

[62] Meiqin Mao, Yinzheng Tao, Liuchen Chang, Yongchao Zhao, Peng Jin "An Intelligent Static Switch Based on Embedded System and its Control Method for a Microgrid" IEEE Innovative Smart Grid Technologies - Asia, vol.6, pp 21 - 24, 2012.

[63] Xisheng Tang, Zhiping Qi, "Energy Storage Control in Renewable Energy Based Microgrid" IEEE Power and Energy Society General Meeting, vol.6, pp 22 - 26, 2012.

[64] Salameh Z.M, Casacca M.A, Lynch W.A, “A Mathematical Model for Lead - Acid Batteries" IEEE Transaction on Energy Conversion, vol.7, pp 93 - 98, 1992. https://doi.org/10.1109/60.124547.

[65] Kousksou T, Bruel P, Jamil A, El Rhafiki T, Zeraouli Y "Energy Storage: Applications and Challenges" Solar Energy Materials and Solar Cells, vol.120, pp $59 \quad-\quad 8014$. https://doi.org/10.1016/j.solmat.2013.08.015.

[66] ChaoyongHou, Xuehao Hu, Dong Hui "Plug and Play Power Electronic Interface applied in Microgrid" International Conference on Electric Utility Deregulation and Restructuring and Power Technologies, vol.6, pp $719-723,2011$

[67] Shuhui Li, Proano J, Dong Zhang "Microgrid Power flow Study in Grid - Connected and Islanding Mode under Different Converter Control Strategies" IEEE Power and Energy Society General Meeting, pp $1-8,2012$.

[68] Marney C, Venkataramanan G "Microgrids in the Evolving Electricity Generation and Delivery Infrastructure" IEEE Power Engineering Society General Meeting, pp 5, 2006.

[69] Katiraei F, Iravani R, Hatziargyriou N, Dimeas A "Microgrids Management” IEEE Power and Energy Magazine, vol.6, pp 54 - 65, 2008. https://doi.org/10.1109/MPE.2008.918702.

[70] Khalifa T, Naik K, Nayak A, “ A survey of Communication protocols for Automatic Meter Reading Applications" Communications Survey Tutorials, IEEE, pp.168 - 182, 2011.

[71] Stanciulescu G, Farhangi H, Palizban A, Stanchev N, "Communication Technologies for BCIT Smart Microgrid" IEEE PES Innovative Smart Grid Technologies (ISGT), pp. 174 - 182, 2012.

[72] Melike Erol-Kantarci B, Kantarci H, Mouftah T, "Cost Aware Smart Microgrid Network Design for a Sustainable Smart Grid" in Proc. Of IEEE GLOBECOM - Workshop on Smart Grid Communications and Networks, pp.1223 - 1227, 2011.

[73] Asad O, Melike Erol-Kantarci H, Mouftah T, "Sensor Networks Web-Services for Demand Side Energy Management Applications in the Smart Grid" in Proc. Of IEEE Consumer Communications and Networking Conference (CCNC), pp.1176 - 1180, 2011. https://doi.org/10.1109/CCNC.2011.5766363.

[74] Sauter T, Lobashov M, "End to End Communication Architecture for Smart Grids" IEEE Transactions on Industrial Electronics, pp.1218 - 1228, 2011. https://doi.org/10.1109/TIE.2010.2070771.

[75] Zhou J, Hu R, Qain Y, "Scalable Distributed Architectures to Support Advanced Metering Infrastructure in Smart Grid" IEEE Transactions on Parallel and Distributed Systems, pp.1632 - 1642, 2012. https://doi.org/10.1109/TPDS.2012.53.

[76] Abdrabou A, "A Wireless Communication Architecture for Smart Grid Distribution Networks" IEEE Systems Journal, pp. 1 - 11, 2014.

[77] Ruiz-Romero, S.; Colmenar-Santos, A.; Mur-Pérez, F.; LópezRey, A. "Integration of distributed generation in the power distribution network: The need for smart grid control systems, communication and equipment for a smart city-Use cases", Renew. Sustain. Energy Rev. pp.223-234, 2014. https://doi.org/10.1016/j.rser.2014.05.082.

[78] Molina-Garcia A, Fuentes J, Gomez-Lazaro E, Bonastre, A. Campelo, J.C.; Serrano, J.J. "Development and assessment of a wireless sensor and actuator network for heating and cooling loads", IEEE Trans. 
Smart

Grid,

pp.1192-1202,

2012

https://doi.org/10.1109/TSG.2012.2187542.

[79] S. Ghildiya, A. K. Mishra, and N. Garg, "An Overview of Wireless Sensor Networks Using ZigBee Technology," International Journal of Advanced Research in Computer Science and Software Engineering, pp. $114-116,2014$.

[80] S. Basha and K. Krisha, "The Design of network Coordinator between ZigBee and GPRS for Remote Monitoring Applications," International Journal of Engineering Science and Technology, pp. 628- 632, 2013 [81] P. Zhang, F. Li, and N. Bhatt, "Next-Generation Monitoring, Analysis and Control for the Future Smart Control Center," IEEE Transactions on Smart Grid, pp. 186 - $192,2010$. https://doi.org/10.1109/TSG.2010.2053855.

[82] T. Zwavashe and R. Duri, "Integrating GSM and ZigBee Wireless Networks for Smart A2 farming Enterprise in Zimbabwe," International Journal of Science and Research (IJSR), pp. 75 - 80, 2014.

[83] D. Kong, T. Li, X. You, X. Sun, B. Wang, and Q. Liu, "The Research of Long-Distance Data Transmission Based on Meterological Sensor Network," International Journal of Future Generation Communication and Networking, pp 59-70, 2014.

[84] Z. Xu, X. Guan, Q.-S. Jia, J. Wu, D. Wang, and S. Chen, “Performance analysis and comparison on energy storage devices for smart building energy management," IEEE Trans. Smart Grid, vol. 3, no. 4, pp. 2136 - 2147, 2012. https://doi.org/10.1109/TSG.2012.2218836.

[85] A. Mohamed, V. Salehi, and O. Mohammed, "Real-time energy management algorithm for mitigation of pulse loads in hybrid microgrids," IEEE Trans. Smart Grid, vol. 3, no. 4, pp. 1911 - 19222012. https://doi.org/10.1109/TSG.2012.2200702.

[86] S. Bahramirad, A. Khodaei, J. Svachula, and J. R. Aguero, "Building resilient integrated grids: One neighborhood at a time," IEEE Electri_c. Mag., vol. 3, no. 1, pp. 48 - 55, Mar. 2015.

[87] A. D. Paquette and D. M. Divan, “Providing improved power quality in microgrids: Dif_culties in competing with existing powerquality solutions," IEEE Ind. Appl. Mag., vol. 20, no. 5, pp. 34 - 43, 2014. https://doi.org/10.1109/MIAS.2013.2288377.

[88] H. Daneshi and H. Khorashadi-Zadeh, "Microgrid energy management system: A study of reliability and economic issues," in Proc. IEEE Power Energy Soc. General Meeting, pp. 1 - 5, 2012 https://doi.org/10.1109/PESGM.2012.6344957.

[89] B. Falahati, A. Kargarian, and Y. Fu, “Timeframe capacity factor reliability model for isolated microgrids with renewable energy resources," in Proc. IEEE Power Energy Soc. General Meeting, pp. 1 - 8, 2012. https://doi.org/10.1109/PESGM.2012.6345546.

[90] J. Hurtt and L. Mili, “'Residential microgrid model for disaster recovery operations," in Proc. IEEE Grenoble PowerTech Conf., pp. 1 - 6 2013. https://doi.org/10.1109/PTC.2013.6652418

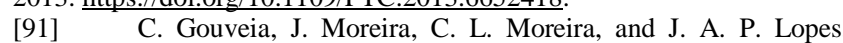
"Coordinating storage and demand response for microgrid emergency operation," IEEE Trans. Smart Grid, vol. 4, no. 4, pp. 1898 - 19082013. https://doi.org/10.1109/TSG.2013.2257895.

[92] H. Qi et al., "Aresilient real-time system design for a secure and recon_gurable power grid," IEEE Trans. Smart Grid, vol. 2, no. 4, pp. 770 - 781, 2011. https://doi.org/10.1109/TSG.2011.2159819.

[93] R. Kalaivani, K. Ramash Kumar, S. Jeevananthan, "Implementation of VSBSMC plus PDIC for Fundamental Positive Output Super Lift-Luo Converter," Journal of Electrical Engineering, Vol. 16, Edition: 4, 2016, pp. 243-258.

[94] K. Ramash Kumar,'Implementation of Sliding Mode Controller plus Proportional Integral Controller for Negative Output Elementary Boost Converter," Alexandria Engineering Journal (Elsevier), 2016, Vol. 55, No. 2, pp. 1429-1445. https://doi.org/10.1016/j.aej.2016.03.027.

[95] P. Sivakumar, V. Rajasekaran, K. Ramash Kumar, "Investigation of Intelligent Controllers for Varibale Speeed PFC Buck-Boost Rectifier Fed BLDC Motor Drive," Journal of Electrical Engineering (Romania), Vol.17, No.4, 2017, pp. 459-471.

[96] K. Ramash Kumar, D.Kalyankumar, DR.V.Kirbakaran" An Hybrid Multi level Inverter Based DSTATCOM Control, Majlesi Journal of Electrical Engineering, Vol. 5. No. 2, pp. 17-22, June 2011, ISSN: 0000-0388.

[97] K. Ramash Kumar, S. Jeevananthan, "A Sliding Mode Control for Positive Output Elementary Luo Converter," Journal of Electrical Engineering, Volume 10/4, December 2010, pp. 115-127.

[98] K. Ramash Kumar, Dr.S. Jeevananthan," Design of a Hybrid Posicast Control for a DC-DC Boost Converter Operated in Continuous Conduction Mode" (IEEE-conference PROCEEDINGS OF ICETECT 2011), pp-240-248, 978-1-4244-7925-2/11.

[99] K. Ramash Kumar, Dr. S. Jeevananthan,” Design of Sliding Mode Control for Negative Output Elementary Super Lift Luo Converter Operated in Continuous Conduction Mode", (IEEE conference Proceeding of ICCCCT-2010), pp. 138-148, 978-1-4244-7768-5/10.
[100] K. Ramash Kumar, S. Jeevananthan, S. Ramamurthy" Improved Performance of the Positive Output Elementary Split InductorType Boost Converter using Sliding Mode Controller plus Fuzzy Logic Controller, WSEAS TRANSACTIONS on SYSTEMS and CONTROL, Volume 9, 2014, pp. 215-228.

[101] N. Arunkumar, T.S. Sivakumaran, K. Ramash Kumar, S. Saranya, "Reduced Order Linear Quadratic Regulator plus Proportional Double Integral Based Controller for a Positive Output Elementary Super Lift Luo-Converter," JOURNAL OF THEORETICAL AND APPLIED INFORMATION TECHNOLOGY, July 2014. Vol. 65 No.3, pp. 890-901.

[102] Arunkumar, T.S. Sivakumaran, K. Ramash Kumar, "Improved Performance of Linear Quadratic Regulator plus Fuzzy Logic Controller for Positive Output Super Lift Luo-Converter," Journal of Electrical Engineering, Vol. 16, Edition:3, 2016, pp. 397-408

[103] Kingston Stanley P, Sanjeevi Gandhi A "INDUSTRIAL EFFLUENT WATER PH NEUTRALIZATION CONTROLLER DESIGN USING LABVIEW AND MATLAB" International Journal of Pure and Applied Mathematics Volume 117 No. 10. (2017), 13-17 doi: 10.12732/ijpam.v117i10.4

[104] Vijay Daniel P, Sanjeevi Gandhi A "DESIGN OF MODELING AND CONTROL OF TEMPERATURE PROCESS INDOWNDRAFT BIOMASS GASIFIER: SIMULATION STUDIES" International Journal of Pure and Applied Mathematics Volume 117 No. 10. (2017), 19-23 doi: 10.12732/ijpam.v117i10.3

[105] Vijay Daniel P, Sanjeevi Gandhi A "Design of Mathematical Modelling and Control of Downdraft Biomass Gasifier" International Journal of Control and Automation Vol. 10, No. 11 pp 175 (2017) https://doi.org/10.14257/ijca.2017.10.11.16

[106] T. Padmapriya, V. Saminadan, "Performance Improvement in long term Evolution-advanced network using multiple imput multiple output technique", Journal of Advanced Research in Dynamical and Control Systems, Vol. 9, Sp-6, pp: 990-1010, 2017.

[107] S. V. Manikanthan and D. Sugandhi "Interference Alignment Techniques For Mimo Multicell Based On Relay Interference Broadcast Channel" International Journal of Emerging Technology in Computer Science \& Electronics (IJETCSE) ISSN: 0976-1353 Volume- 7, Issue 1 MARCH 2014.

[108] P Bala Gopal, K Hari Kishore, B.Praveen Kittu "An FPGA Implementation of On Chip UART Testing with BIST Techniques", International Journal of Applied Engineering Research, ISSN 0973-4562, Volume 10, Number 14 , pp. 34047-34051, August 2015.

[109] N. Arunkumar, T.S. Sivakumaran, K. Ramash Kumar, S. Saranya, "Reduced Order Linear Quadratic Regulator plus Proportional Double Integral Based Controller for a Positive Output Elementary Super Lift Luo-Converter," JOURNAL OF THEORETICAL AND APPLIED INFORMATION TECHNOLOGY, July 2014. Vol. 65 No.3, pp. 890-901. 